\title{
Physical exercise programs at Basic Healthcare Units decrease body fat and improve the functional capacity of women over 50 years old
}

\author{
Fabrício Eduardo Rossil ${ }^{1 *}$, Anderson Rogério Lecca² ${ }^{2}$ Luiz Gustavo Perón Martins² , Luciana Sanae Ota Takahashi², \\ Diego Giuliano Destro Christofaro ${ }^{3}$, Luís Alberto Gobbo ${ }^{3}$, Ismael F. Freitas $\mathrm{Jr}^{3}$ \\ 'Department of Physical Education, Federal University of Piaú (UFPI), Teresina, Brazil \\ 2Department of Physical Education, University of Dracena, Dracena, Brazil \\ ${ }^{3}$ Postgraduation Program in Movement Sciences, Department of Physical Education, São Paulo State University (UNESP), Presidente Prudente, Brazil
}

This study verified the effects of a physical exercise program performed at Basic Healthcare Units on the body composition and functional capacity of women over 50 years old and to compare these variables according to age. Forty-eight women (age, $65.4 \pm 7.3$ years) were assessed. The program lasted 20 weeks, and was conducted 2 times per week, $60 \mathrm{~min} /$ day. Body mass and height were collected and body mass index (BMI) was calculated. Bioelectrical impedance was used to estimate fat mass and fat free mass. Functional capacities: handgrip test, Timed Up and Go (TUG) test, and Guralnick test were assessment. Weight $(68.7 \pm 12.5$ [pre] $\times 66.8 \pm 12.5$ [post], $P<0.001)$, BMI $(28.5 \pm 4.1 \mathrm{~kg} /$ $\mathrm{m}^{2}$ [pre] $\times 27.6 \pm 4.0 \mathrm{~kg} / \mathrm{m}^{2}$ [post], $\left.P<0.001\right)$, and fat mass $(28.4 \pm 7.8 \mathrm{~kg}$ [pre] $\times 26.4 \pm 7.3 \mathrm{~kg}$ [post], $P<0.001)$ were decreased. For functional capacity, handgrip $(21.2 \pm 5.8 \mathrm{~kg}$ [pre] $\times 22.9 \pm 6.9 \mathrm{~kg}$ [post], $P=0.014)$, lower limb strength $(12.0 \pm 3.0 \mathrm{sec}$ [pre] $\times 8.5 \pm 2.2 \mathrm{sec}$ [post], $P<0.001)$, TUG $(8.4 \pm 1.5 \mathrm{sec}$ [pre] $\times 7.6 \pm 1.1$ se [post], $P<0.001)$ and Guralnik tests $(10.6 \pm 1.6$ [pre] $\times 11.8 \pm 0.5$ [post], $P<0.001)$ were improved. 20 weeks of exercise program performed at Basic Healthcare Units decreased body fat and improvement of functional capacity of women over 50 years old and there was difference according to age only on the body composition variables.

Keywords: Elderly, Exercise, Health care

\section{INTRODUCTION}

Aging is strongly associated with changes in body composition. When associated with a sedentary lifestyle, the increase in the percentage of body fat is due to an increase in body fat as well as a decrease in lean mass. An increase in fat mass and body fat percentage can be observed because of the loss of skeletal muscle mass, and, concomitantly, there is also a loss of muscle strength with aging (Schaap et al., 2013). Metabolic changes originating from these behaviors may contribute to the development of morbidities such as type 2 diabetes mellitus, hypertension, dyslipidemia, atherosclerosis and cancer (Lloyd-Jones et al., 2009; Matsu- da and Shimomura, 2013).

Another factor to consider is the reduction of physical activity that occurs mainly with advancing age (Centers for Disease Control and Prevention, 2005). With a sedentary lifestyle, age-related changes in body composition and muscle strength, are associated with functional decline (Schaap et al., 2013), as are decreases in neuro-skeletal function, balance, mobility and walking speed (Vincent et al, 2010), and an increase in the prevalence of falls and fractures due to frailty (Tatsuno et al., 2013), which worsens the ability of enjoying independence in activities of daily living (ADLs) and quality of life.

The increase of chronic diseases for this population, besides a

\footnotetext{
${ }^{*}$ Corresponding author: Fabrício Eduardo Rossi

(iD) http://orcid.org/0000-0002-0594-2529

Department of Physical Education, Paulista State University, "Júlio Mesquita Filho". Roberto Simonsen Street. n⿳ 305 - Education Center. Presidente Prudente. 19060900. São Paulo. Brazil

Tel: +55-18-3229-5828, Fax. +55-18-3221-4391, E-mail: rossifabricio@yahoo.com.br Received: May 9, 2017 / Accepted: June 11, 2017
}

This is an Open Access article distributed under the terms of the Creative Commons Attribution Non-Commercial License (http://creativecommons.org/licenses/by-nc/4.0/) which permits unrestricted non-commercial use, distribution, and reproduction in any medium, provided the original work is properly cited. 
reduction in quality of life, can result in higher spending on public health. In 2004, in Brazil, according The Brazilian Institute of Geography and Statistics (IBGE, 2004), the cost for the treatment of chronic diseases in public health was approximately 30.8 billion $(\mathrm{R} \$)$, corresponding to 9,640.00 ( $\mathrm{R} \$$ ) per year/per patient.

Studies have shown that regular physical activity can be an inexpensive tool and effective in reducing disorders among the elderly (Barnett et al., 2003; Karinkanta et al., 2009; Madureira et al., 2010). It is known that physically activity people have lower morbidity and mortality rates (Gabriel et al., 2011), and physical activity is an interesting strategy for reducing the cost of health services and medicines (Codogno et al., 2012).

Although the benefits of different kinds of exercise for older people have been extensively discussed in the literature (Nelson et al., 2007), there are no longitudinal studies covering 16 weeks of intervention and investigating the effect of aerobic and resistance training in women over 50 years old and that have attended a Basic Healthcare Units (BHU). Thus, this study aimed to verify the effects of a physical exercise program, hosted at BHU, on body composition and the functional capacity of women over 50 years old, and to compare these variables according to age.

\section{MATERIALS AND METHODS}

\section{Subjects}

The study included women over 50 years old who participated in an exercise program, which was called "Viva a Vida" and was developed at Faculdade de Dracena/Fundação Dracenense de Educação e Cultura (FUNDEC), Dracena, São Paulo, Brazil. Dracena is a city in southeastern Brazil (43.263.00 inhabitants) with a human development index of 0.776 (IBGE, 2010). To be included in the study the participants had to meet the following criteria: (a) be women; (b) be older than 50 years old on the date that the assessment was conducted; (c) not present any physical limitations or health problems that could prevent the completion of the assessments and exercise interventions (i.e., absence of limbs, hurting joints); (d) present medical permission to participate in the training; (e) have signed the consent form. After being informed of the risks and benefits involved in the study, the participants signed an informed consent. The project was approved by the Ethics Research Group of the University (CAAE: 15995113.8. 0000.5402) and the research was conducted according to the Declaration of Helsinki, 2008 revision.

We performed a power analysis for the design of this study, and it was based on the observations from another, previous study that was conducted to verify the effects of engaging in physical activity and following dietary orientations on anthropometrics, biochemist and homodynamic variables in users of a Basic Healthcare Unit in Vitória- ES. That study verified a reduction in weight of 5.6 $\mathrm{kg}$ (Venturim and Cade, 2012). Our primary hypothesis was that this difference would be statistically significant as compared to the control group assessed during the same time period, with a power (1-type II error) of 0.80 and a type I error of 0.05 . Using PS software (ver 3.1.2, Dupont and Plummer, http://biostat. mc.vanderbilt.edu/wiki/Main/PowerSampleSize), it was estimated that we would need 41 subjects. Considering a dropout rate of $25 \%-40 \%$, we over-recruited the number of subjects.

A total of 77 women were evaluated at baseline, however, those participants that were absent for three consecutive sessions, or for four nonconsecutive sessions in 1 month were excluded from the final analysis. Accordingly, only those participants that attended $80 \%$ or more of the training program were analyzed. Thus, the final analysis was conducted with 48 subjects. The reasons for dropouts included personal/family problems and unspecified reasons.

\section{Procedures}

This intervention study was carried out from March to August of 2014 at BHU. The assessment occurred at baseline and after 20 weeks of intervention at the FUNDEC laboratory and consisted of anamnesis to verify whether the participants met the inclusion criteria. Anthropometry, body composition and functional capacity were evaluated.

\section{Anthropometric measurements and body composition}

Anthropometry was composed of body weight and height measurements. Height was measured on a fixed-stadiometer, Sanny brand stadiometer, with an accuracy of $0.1 \mathrm{~cm}$ and a length of $2.20 \mathrm{~m}$. Body weight was measured using an electronic scale (Sanny brand, São Paulo, Brazil), with a precision of $0.1 \mathrm{~kg}$. Afterward, the Body mass index is calculated as weight in kilograms divided by height in meters squared.

Bioimpedance analysis (BIA) was performed using a single-frequency 50-kHz analyzer (BIA Analyzer -101Q, RJL Systems, Charter Twp of Clinton, MI, USA). Measurements were obtained from the right hand and right foot. After recording values of resistance $(\mathrm{R})$ and reactance $(\mathrm{Xc})$, estimates of fat free mass and fat mass were obtained from sex-specific BIA prediction equations recently developed by Lohman et al. (1988) (fat free mass $[\mathrm{kg}]=$ $\left.0,474\left[\mathrm{AL}^{2} / \mathrm{R}\right]+0,180[\mathrm{PC}]+7,3\right)$. 


\section{Functional capacity}

Handgrip was measured on the dominant side, using an electronic hand dynamometer (EH101, Camry, Guangdong, China) with a precision of $0.1 \mathrm{~kg}$. The dynamometer was adjusted so that it fit comfortably to the subject's hand size in order to obtain their best performance. Participants, while seated with elbow bent at a position of $90^{\circ}$, were instructed to grip the dynamometer with maximum strength with the dynamometer facing outwards the body. Three trials were performed, with a rest period of at least 1 min between trials. The highest value was used as handgrip strength (Ali et al., 2008).

The Guralnik Short Physical Performance Battery (Guralnik et al., 1995) validity and reliability for Brazil older adults (Freire et al., 2012) was used to verify the functional capacity, in three different tests: balance, gait speed, and chair stand. Before each test, the interviewer explained and demonstrated the task and made sure the exercise could be done without risk to the elderly. In Balance Tests, the seniors were asked to perform each of the following tasks in sequence (10 sec): side-by-side stand, semitandem stand and full tandem stand. The performance alternatives were: unable, 0 point; carried out only a side-by-side stand position, 1 point; successful at a side-by-side stand and in a semitandem stand, 2 points; the two tests plus the full tandem stand from 3 to $9.9 \mathrm{sec}$, 3 points; full tandem stand (10 sec), 4 points. In the Gait Speed test, subjects were asked to walk a distance of $4 \mathrm{~m}$ at their daily speed, twice. Time was recorded, and performance was identified according to the following times: $<4.82 \mathrm{sec}, 4 ;<6.2 \mathrm{sec}, 3 ;<8.7$ sec, 2; $\geq 8.7 \mathrm{sec}, 1$. At the Timed Chair Stand test, the subjects were asked to fold their hands on the opposite shoulder crossed at the wrists and stand up and sit down 5 times as quickly as possible. To assess the performance, the following score was applied: $\leq 11.2 \mathrm{sec}, 4 ; \leq 13.7 \mathrm{sec}, 3 ; \leq 16.7 \mathrm{sec}, 2 ; \leq 61 \mathrm{sec}, 1 ;$ and $>61$ sec, 0 . A scale, based on the sum of the scores (0 to 12) obtained in the three tests identified subjects with functional limitations (score $<9$ points) or normal ( $\geq 9$ points).

For the Timed Up and Go (TUG) test, the time in seconds required for the participants to "rise from a standard arm chair, walk at your typical or normal pace to a line on the floor $3 \mathrm{~m}$ away, turn, return, and sit down again" were registered. Those who completed the TUG test in more than 14 sec also showed lower scores on the Berg Balance Scale, which was associated with higher risk for institutionalization (Podsiadlo and Richardson, 1991).

\section{Exercise protocol}

The exercise program was performed 2 times per week on non- consecutive days, for approximately $70 \mathrm{~min}$ per day. The routine comprised five minutes of warm-up, $30 \mathrm{~min}$ of resistance training, $30 \mathrm{~min}$ of aerobic training and five minutes of stretching at the end, according to American College of Sports Medicine (ACSM) (Nelson et al., 2007). At the beginning of the activities, a 2-week period of familiarization was conducted for both the aerobic and the resistance exercises. The intensity of the resistance training was controlled through the zone of maximum repetitions (RM). The series were executed until momentary exhaustion, meaning that, when participants performed the training with repetitions varying from 12 to $15 \mathrm{RM}$, they were always stimulated to execute at least 12 and no more than 15 repetitions. In the case of the participants executing more than 15 repetitions, the overload was increased in order to have the training zone respected (Silva et al., 2006). The rate perception of effort was determined at the end of each session (Borg et al., 1987). All training sessions were conducted under the supervision of physical education professionals and trainees who had been previously familiarized with the training program.

\section{Statistical analysis}

A descriptive analysis was carried out for the sample characterization. The Kolmogorov-Smirnov test analyzed the data set distribution. To verify the differences between the baseline moment and postintervention, the Student $t$-test for dependent samples was used if the data presented normal distribution. If the data did not show normal distribution, the Wilcoxon test was applied. The comparison between groups according to age $(<64.7$ and $\geq 64.7$ years old) was performed using two-way analysis of variance (group $\times$ time) and the Bonferroni post hoc test to identify any specific interactions. For all measured variables, the estimated sphericity was verified according to Mauchly W test, and the Greenhouse-Geisser correction was used when necessary. All analyses were performed using the statistical software BioEstat (ver. 5.0). The level of significance was set at $5 \%$.

\section{RESULTS}

Table 1 presents the sample characteristics in mean and standard deviation. In general the sample can be considered elderly, because the average age was higher than 65 years. Furthermore, it can be observed that the participants this study were overweight $\left(\mathrm{BMI}>24.9 \mathrm{~kg} / \mathrm{m}^{2}\right)$.

Table 2 presents the changes in the values of the body composition and functional capacity after 20 weeks of exercise. It can be 
seen that there were statistically significant decreases for weight, BMI and fat mass and percentage of fat mass $(P<0.001)$. There was no statistically significant difference in fat-free mass, however, as it was maintained postintervention $(P=0.700)$.

Regarding functional capacity, statistically significant differences were observed on handgrip (8\%), improve lower limb strength [time, -29\%]), TUG test (-9.5) and Guralnik points (11.1\%). Balance and gait speed were improved but were not statistically significant $(P>0.05)$.

Table 1. General characteristics of the sample $(n=48)$

\begin{tabular}{lc}
\hline Variable & Mean \pm SD \\
\hline Age $(\mathrm{yr})$ & $65.4 \pm 7.3$ \\
Height $(\mathrm{cm})$ & $154.5 \pm 5.9$ \\
Weight $(\mathrm{kg})$ & $68.1 \pm 12.1$ \\
Body mass index $\left(\mathrm{kg} / \mathrm{cm}^{2}\right)$ & $28.4 \pm 4.0$ \\
\hline
\end{tabular}

$\mathrm{SD}$, standard deviation.
Table 3 showed the comparison on the body composition and functional capacity according to age.

When analyzed weight, body mass index, body composition and functional capacity according to of the average age, there were statistically significant differences across time for weight $(F=56.2$, $P<0.001)$, IMC $(F=58.4, P<0.001)$, fat mass $(F=62.2, P<$ $0.001)$, percentage of fat mass $(F=28.2, P<0.001)$, and for functional capacity, handgrip $(F=6.4, P=0.01)$, lower limb strength $(F=43.7, P<0.001)$, TUG $(F=24.7, P<0.001)$, and Guralnik tests $(F=24.2, P<0.001)$. There was an interaction (time $\times$ group) only on the body composition variables, fat mass $(F=13.4, P=$ $0.001)$, percentage of fat mass $(F=15.6, P<0.001)$, and fat-free mass $(F=16.0, P<0.001)$. Statistically significant differences between groups were observed for weight $(F=7.1, P=0.01)$, fat mass $(F=8.0, P=0.007)$, percentage of fat mass $(F=5.0, P=0.03)$, and fat-free mass $(F=6.3, P=0.01)$. There were no differences between groups for functional capacity.

Table 2. Body composition and functional capacity values after 20 weeks of exercise

\begin{tabular}{|c|c|c|c|c|}
\hline Variable & Pre $(n=48)$ & Post $(n=48)$ & $\Delta \%$ & $P$-value \\
\hline Weight (kg) & $68.7 \pm 12.5$ & $66.8 \pm 12.5$ & -2.8 & $<0.001$ \\
\hline Body mass index $\left(\mathrm{kg} / \mathrm{m}^{2}\right)$ & $28.5 \pm 4.1$ & $27.6 \pm 4.0$ & -2.8 & $<0.001$ \\
\hline Fat mass $(\mathrm{kg})$ & $28.4 \pm 7.8$ & $26.4 \pm 7.3$ & -7.2 & $<0.001$ \\
\hline Fat mass (\%) & $40.7 \pm 4.4$ & $38.9 \pm 4.4$ & -4.3 & $<0.001$ \\
\hline Fat-free mass (kg) & $40.3 \pm 5.2$ & $40.4 \pm 5.9$ & 0.2 & 0.700 \\
\hline Handgrip (kg) & $21.2 \pm 5.8$ & $22.9 \pm 6.9$ & 8.0 & 0.014 \\
\hline Lower limb strength (sec) & $12.0 \pm 3.0$ & $8.5 \pm 2.2$ & -29.0 & $<0.001$ \\
\hline Timed Up and Go test (time-sec) & $8.4 \pm 1.5$ & $7.6 \pm 1.1$ & -9.5 & $<0.001$ \\
\hline Walking 4 m (time-sec) & $4.0 \pm 1.6$ & $3.6 \pm 0.5$ & -9.5 & 0.089 \\
\hline Balance (point) & $3.8 \pm 0.6$ & $3.9 \pm 0.3$ & 4.1 & 0.130 \\
\hline Guralnik (point) & $10.6 \pm 1.6$ & $11.8 \pm 0.5$ & 11.1 & $<0.001$ \\
\hline
\end{tabular}

Values are presented as mean \pm standard deviation.

Table 3. Comparison of body composition and functional capacity according to age

\begin{tabular}{|c|c|c|c|c|}
\hline \multirow{2}{*}{ Variable } & \multicolumn{2}{|c|}{$<64.7 \mathrm{yr}(\mathrm{n}=24)$} & \multicolumn{2}{|c|}{$\geq 64.7 \mathrm{yr}(\mathrm{n}=24)$} \\
\hline & Baseline & Post & Baseline & Post \\
\hline Weight (kg) & $72.8 \pm 12.7$ & $70.7 \pm 12.6^{*}$ & $63.5 \pm 9.6$ & $61.5 \pm 9.7^{*, \#}$ \\
\hline Body mass index $\left(\mathrm{kg} / \mathrm{cm}^{2}\right)$ & $29.9 \pm 4.0$ & $29.0 \pm 4.1^{*}$ & $27.0 \pm 3.4$ & $26.1 \pm 3.5^{*, *}$ \\
\hline Fat mass $(\mathrm{kg})$ & $31.3 \pm 8.1$ & $28.5 \pm 7.8^{*}$ & $24.8 \pm 5.6$ & $23.8 \pm 5.6^{*, *}$ \\
\hline Fat mass $(\%)$ & $42.4 \pm 4.2$ & $39.7 \pm 4.4^{*}$ & $38.7 \pm 3.7$ & $38.3 \pm 4.3^{*, *}$ \\
\hline Fat-free mass (kg) & $41.5 \pm 5.2$ & $42.3 \pm 5.5^{*}$ & $38.7 \pm 4.6$ & $37.7 \pm 5.1^{*, *}$ \\
\hline Handgrip (kg) & $22.1 \pm 6.1$ & $24.5 \pm 8.7$ & $19.5 \pm 4.9$ & $21.4 \pm 4.5$ \\
\hline Lower limbs strength (sec) & $11.6 \pm 2.3$ & $8.4 \pm 1.6^{*}$ & $12.2 \pm 3.5$ & $8.7 \pm 2.8^{*}$ \\
\hline Timed Up and Go test (sec) & $8.1 \pm 0.9$ & $7.4 \pm 0.8^{*}$ & $8.8 \pm 1.8$ & $7.9 \pm 1.2^{*}$ \\
\hline Guralnick tests (point) & $10.9 \pm 1.3$ & $11.9 \pm 0.4^{*}$ & $10.3 \pm 1.9$ & $11.7 \pm 0.6^{*}$ \\
\hline
\end{tabular}

Values are presented as mean \pm standard deviation.

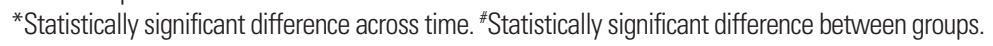




\section{DISCUSSION}

The main finding of the present study was that after 20 weeks of a physical exercise program performed at BHU there was a decrease in weight, BMI, fat mass, and percentage of fat mass and improvement in the functional capacity of women over 50 years of age. When comparing the participants according to age, there were statistically significant differences between groups for all body composition variables. However, in relation to functional capacity there were differences only across time.

In agreement with our results, a study verified the effect of practicing physical activity and the dietary orientation in obese users of BHU and observed significant reduction in weight, BMI, and percentage of body fat after eleven months of intervention (Venturim and Cade, 2012). Obesity is considered a major public health problem (Ghorbani et al., 2013) and is directly related to increased morbidities such as metabolic syndrome, cardiovascular disease and cancer (Aballay et al., 2013), increasing the costs for the treatment of these chronic diseases (IBGE, 2004). Thus, strategies that minimize the accumulation of body fat are important. In a study that observed differences in healthcare costs according to the level of physical activity in 121 type 2 diabetic patients interviewed at two BHU in Bauru, Brazil, concluded that sedentary type 2 diabetic patients presented higher healthcare costs related to doctor visits and medicine purchase (Codogno et al., 2012). Furthermore, the maintenance of fat-free mass during a weight-reduction program can improve independence for ADLs by increasing strength, mobility and balance (Marques et al., 2011).

A survey in Japan revealed that bone fracture was closely associated with not only low bone mass but also age, fall, diabetes mellitus, kidney disease, menopause, and lifestyle factors of dieting, exercise, and alcohol. Women's health care focusing on lifestyle-related fracture risks such as dieting and exercise appear necessary to preventing diseases in the postmenopausal period (Tatsuno et al., 2013). It is known that physically active people have lower morbidity and mortality rates (Gabriel et al., 2011). In this sense, beneficial changes were observed in the body composition of the participants of this study.

A meta-analysis of epidemiological studies investigating physical activity and primary prevention of coronary heart disease (Sattelmair et al., 2011) observed that at a higher level of physical activity, the relative risks were lower and people who were physically active at levels lower than the minimum recommended amount also had significantly lower risk of coronary heart disease. Furthermore, studies have shown that physical activity reduces the risk of cognitive decline, such as occurs in Alzheimer disease (Lautenschlager et al., 2008).

In relation to functional capacity, there were improvements in all the variables analyzed. Contributing with our found, a study verified the effects of a physical activity program in elderly people during one year and concluded that regular physical activity could reverse or slow the decline in motor performance related to aging and improved balance and choice reaction time (Petroski, 2012). In study with 163 people over 65 years of age was concluded that participation in a weekly group exercise program with ancillary home exercises can improve balance and reduce the rate of falling in the community of at risk older people (Barnett et al., 2003). The improvement of the components of strength, mobility, and balance as evaluated in this study are very important because this population can subsequently perform the ADL with security and efficiency, decreasing the risk of falls and fractures due to frailty. Furthermore, handgrip strength can be a predictor of all causes of mortality among the oldest of the elderly population and may serve as a convenient tool for predicting mortality risk among elderly people (Ling et al., 2010).

We highlighted as positive the fact that the intervention through physical exercise have was long-term (20 weeks) and was performed for about 150 min per week based on the suggestions of the ACSM (Nelson et al., 2007). It is further considered a new intervention to carry out this program with people who use public health systems in an attempt to extrapolate possible health-promoting actions for the prevention of cardiovascular risk and possible future reduction in government health costs. Among the limitations of this study, we must cite the absence of nutritional control and control group. Thus it is suggested that further study of portion control and the amount of calories ingested daily by the participants in order to control food intake and compared with a sedentary group.

In conclusion, physical exercise programs held over 20 weeks in BHU decrease body fat and improve the functional capacity of women over 50 years of age, and there was difference according to age only on the body composition variables. Programs of this kind could be a useful strategy for improving health status and preventing some disorders related to sedentary habits during the aging. Furthermore, it may be an effective non-pharmacological strategy in the prevention and treatment of obesity and mobility disability in older adults, thereby decreasing intake of medication. 


\section{CONFLICT OF INTEREST}

No potential conflict of interest relevant to this article was reported.

\section{ACKNOWLEDGMENTS}

This study was supported by the São Paulo Research Foundation (FAPESP; 2013/25310-2).

\section{REFERENCES}

Aballay LR, Eynard AR, Díaz Mdel P, Navarro A, Muñoz SE. Overweight and obesity: a review of their relationship to metabolic syndrome, cardiovascular disease, and cancer in South America. Nutr Rev 2013;71: 168-179.

Ali NA, O'Brien JM Jr, Hoffmann SP, Phillips G, Garland A, Finley JC, Almoosa K, Hejal R, Wolf KM, Lemeshow S, Connors AF Jr, Marsh CB; Midwest Critical Care Consortium. Acquired weakness, handgrip strength, and mortality in critically ill patients. Am J Respir Crit Care Med 2008;178:261-268.

Barnett A, Smith B, Lord SR, Williams M, Baumand A. Community-based group exercise improves balance and reduces falls in at-risk older people: a randomised controlled trial. Age Ageing 2003;32:407-414.

Borg G, Hassmén P, Lagerström M. Perceived exertion related to heart rate and blood lactate during arm and leg exercise. Eur J Appl Physiol Occup Physiol 1987;56:679-685.

Centers for Disease Control and Prevention (CDC). Trends in leisure-time physical inactivity by age, sex, and race/ethnicity--United States, 19942004. MMWR Morb Mortal Wkly Rep 2005;54:991-994.

Codogno JS, Fernandes RA, Monteiro HL. Physical activity and healthcare cost of type 2 diabetic patients seen at basic units of healthcare. Arq Bras Endocrinol Metabol 2012;56:6-11.

Freire AN, Guerra RO, Alvarado B, Guralnik JM, Zunzunegui MV. Validity and reliability of the short physical performance battery in two diverse older adult populations in Quebec and Brazil. J Aging Health 2012;24:863-878.

Gabriel KK, Conroy MB, Schmid KK, Storti KL, High RR, Underwood DA, Kriska AM, Kuller LH. The impact of weight and fat mass loss and increased physical activity on physical function in overweight, postmenopausal women: results from the Women on the Move Through Activity and Nutrition study. Menopause 2011;18:759-765.

Ghorbani A, Ziaee A, Oveisi S, Afaghi A. A comparison of health-related quality of life among normal-weight, overweight and obese adults in Qazvin metabolic diseases study (QMDS), Iran. Glob J Health Sci

\section{3;5:156-162.}

Guralnik JM, Ferrucci L, Simonsick EM, Salive ME, Wallace RB. Lower-extremity function in persons over the age of 70 years as a predictor of subsequent disability. N Engl J Med 1995;332:556-561.

Karinkanta S, Heinonen A, Sievänen H, Uusi-Rasi K, Fogelholm M, Kannus $P$. Maintenance of exercise-induced benefits in physical functioning and bone among elderly women. Osteoporos Int 2009;20:665-674.

Lautenschlager NT, Cox KL, Flicker L, Foster JK, van Bockxmeer FM, Xiao J, Greenop KR, Almeida OP. Effect of physical activity on cognitive function in older adults at risk for Alzheimer disease: a randomized trial. JAMA 2008;300:1027-1037.

Ling CH, Taekema D, de Craen AJ, Gussekloo J, Westendorp RG, Maier $\mathrm{AB}$. Handgrip strength and mortality in the oldest old population: the Leiden 85-plus study. CMAJ 2010;182:429-435.

Lloyd-Jones D, Adams R, Carnethon M, De Simone G, Ferguson TB, Flegal K, Ford E, Furie K, Go A, Greenlund K, Haase N, Hailpern S, Ho M, Howard V, Kissela B, Kittner S, Lackland D, Lisabeth L, Marelli A, McDermott M, Meigs J, Mozaffarian D, Nichol G, O’Donnell C, Roger V, Rosamond W, Sacco R, Sorlie P, Stafford R, Steinberger J, Thom T, Wasserthiel-Smoller S, Wong N, Wylie-Rosett J, Hong Y; American Heart Association Statistics Committee and Stroke Statistics Subcommittee. Heart disease and stroke statistics--2009 update: a report from the American Heart Association Statistics Committee and Stroke Statistics Subcommittee. Circulation 2009;119:480-486.

Lohman T, Roache A, Martorell R. Anthropometric standardization reference manual. Champaign (IL): Human Kinetics Books; 1988.

Madureira MM, Bonfá E, Takayama L, Pereira RM. A 12-month randomized controlled trial of balance training in elderly women with osteoporosis: improvement of quality of life. Maturitas 2010;66:206-211.

Marques EA, Mota J, Machado L, Sousa F, Coelho M, Moreira P, Carvalho J. Multicomponent training program with weight-bearing exercises elicits favorable bone density, muscle strength, and balance adaptations in older women. Calcif Tissue Int 2011;88:117-129.

Matsuda M, Shimomura I. Increased oxidative stress in obesity: implications for metabolic syndrome, diabetes, hypertension, dyslipidemia, atherosclerosis, and cancer. Obes Res Clin Pract 2013;7:e330-341.

Nelson ME, Rejeski WJ, Blair SN, Duncan PW, Judge JO, King AC, Macera CA, Castaneda-Sceppa C; American College of Sports Medicine; American Heart Association. Physical activity and public health in older adults: recommendation from the American College of Sports Medicine and the American Heart Association. Circulation 2007;116: 1094-1105.

Petroski EC. Effects of a physical activities for elderly people. Rev Bras Ativ Fís Saúde 2012;2:34-40.

Podsiadlo D, Richardson S. The timed "Up \& Go": a test of basic function- 
al mobility for frail elderly persons. J Am Geriatr Soc 1991;39:142-148.

Sattelmair J, Pertman J, Ding EL, Kohl HW 3rd, Haskell W, Lee IM. Dose response between physical activity and risk of coronary heart disease: a meta-analysis. Circulation 2011;124:789-795.

Schaap LA, Koster A, Visser M. Adiposity, muscle mass, and muscle strength in relation to functional decline in older persons. Epidemiol Rev 2013;35:51-65.

Silva CM, Gurjão AL, Ferreira L, Gobbi LT, Gobbi S. Efeito do treinamento com pesos, prescrito por zona de repetições máximas, na força muscular e composição corporal em idosas. Rev Bras Cineantropom Desempenho Hum 2006;8:39-45

Tatsuno I, Terano T, Nakamura M, Suzuki K, Kubota K, Yamaguchi J, Yoshida T, Suzuki S, Tanaka T, Shozu M. Lifestyle and osteoporosis in middle-aged and elderly women: Chiba bone survey. Endocr J 2013; 60:643-650.

The Brazilian Institute of Geography and Statistics - IBGE. Censo demográfico e contagem da população: população residente por sexo, situação e grupos de idade. Rio de Janeiro (Brazil): IBGE; 2004.

The Brazilian Institute of Geography and Statistics - IBGE. Censo demográfico e contagem da população: população residente por sexo, situação e grupos de idade. Rio de Janeiro (Brazil): IBGE; 2010.

Venturim LM, Cade NV. Efeitos do programa "PESO"(Promoção de Estilo de vida Saudável na Obesidade) sobre variáveis antropométricas, hemodinâmicas e bioquímicas. Rev Bras Ativ Fís Saúde 2012;12:19-26

Vincent HK, Vincent KR, Lamb KM. Obesity and mobility disability in the older adult. Obes Rev 2010;11:568-579. 